\title{
ÇEYREK AYNA SÜZGEÇ BANKASI TASARIMI İÇİN YENİ BİR YÖNTEM
}

\author{
Nurhan KARABOĞA ${ }^{\mathbf{1}}$, Bircan KAMIŞLIOĞLU ${ }^{2}$ \\ ${ }^{1}$ Erciyes Üniversitesi, Mühendislik Fakültesi, Elektrik Elektronik Mühendisliği Bölümü, Kayseri \\ ${ }^{2}$ Fırat Üniversitesi, Mühendislik Fakültesi, Elektrik Elektronik Mühendisliği Bölümü, Elazığ \\ nurhank@erciyes.edu.tr, bkamislioglu@firat.edu.tr
}

(Geliş/Received: 17.07.2014; Kabul/Accepted: 09.11.2014)

ÖZET

Son yıllarda süzgeç bankası yapıları işaret işlemede, haberleşme sistemlerinde, biyomedikal işaret işlemede, alt bant kodlama işlemlerinde oldukça sık kullanılmaktadır. Süzgeç bankası tasarımında özellikle çok önemli bir yere sahip olan frekans seçiciliği, süzgeç bankasının farklı frekans bantlarındaki başarımını gösteren bir ölçüttür. İyi bir frekans seçiciliği için süzgeç bankasının yüksek oranda durdurma bandı azalmasına ve dar bir geçiş bandına sahip olması gerekir. Süzgeç bankası tasarımında iteratif ve optimizasyona dayalı yöntemler kullanılmaktadır. İteratif yöntemlere örnek olarak Hooke ve Jeeves algoritması, Parks-McClellan algoritması, Lagrange fonksiyonları yöntemi, Fibonacci denklemleri, Golden arama algoritması verilebilir. Bu çalışmada, iteratif yöntem olarak bilinen ve en küçük hata ile istenen optimum dürtü yanıtını sağlayan en iyi yöntemlerden biri olan Parks-McClellan algoritması temel alınmış ve ilk örnek süzgecin kesim frekansının optimize edilmesine dayalı bir algoritma geliştirilmiştir. Bu çalışmada, ilk örnek süzgecin kesim frekansının optimize edilmesine dayalı yeni bir algoritma geliştirilmiştir. Süzgeç tasarımında pencereleme tekniği temel alınarak önerilen yeni pencere, çeyrek ayna süzgeç (QMF-Quadrature Mirror Filter) bankası tasarımında kullanılmış ve tasarlanan süzgeç bankasının etkinliği iki farklı giriş işareti üzerinde test edilerek gösterilmiştir.

Anahtar Kelimeler: QMF bankası, kaiser penceresi, cosh penceresi, kaiser-cosh penceresi

\section{A NEW METHOD FOR QUARTER MIRROR FILTER BANK DESIGN}

\begin{abstract}
In recent years multirate filter banks, which are part of the system structures in signal processing and communication systems, biomedical signal processing, the sub-bands coding processing are often used. A very important place, especially in the design of filter banks having frequency selectivity, the filter bank is a measure of the performance of different frequency bands. Filter bank must have high stop band attenuation and narrow pass band for good frequency selectivity of the filter bank. In the design and optimization based on filter banks, iterative methods are used. Iterative methods can be exampled such as Hooke and Jeeves algorithm, the ParksMcClellan algorithm, Lagrangian method, Fibonacci equations, Golden search algorithm. This study is based on Parks-McClellan algorithm which is known iterative method, provides desired optimal impulse response with minimal error rate and is one of the best known technique. In this study, a new algorithm which is based on optimizing the cutoff frequency of prototype filter has been developed. Based on windowing technique filter design with the proposed new QMF-Quadrature Mirror Filter bank designed. Designed filter banks effectiveness is tested on two different input signals and showed with figures.
\end{abstract}

Key Words: QMF bank, kaiser window, cosh window, kaiser-cosh window

\section{GÍRISS (INTRODUCTION)}

Son yıllarda Çeyrek Ayna Süzgeç-QMF (Quadrature Mirror Filter) bankası literatürde oldukça geniş bir uygulama alanı bulmuştur. Sayısal süzgeç bankaları; haberleşme sistemleri, güç sistemleri ağı, kelime kodlama, kısa zamanlı spektral analiz multimedya sistemler, bir boyutlu ve çok boyutlu işaret işleme, ses ve biyomedikal işaret işleme gibi çoklu hızlı sistemlerin en temel parçasıdır [1-6]. 1980'de Johnston iki kanallı doğrusal fazlı QMF bankası uygulamasını gerçekleştirmiştir. ALD (Aliasing Distortion-Örtüşme Bozulması) ve PHD (Phase Distortion-Faz Bozulması)'nin olmadığı QMF bankası tasarımı için alçak geçiren analiz süzgecin katsayılarını optimize ederek AMD (Amplitude 
Distortion-Genlik Bozulması)'yi minimize etmiştir [2]. Chen ve Lee frekans düzleminde hata fonksiyonunun doğrusal olması için iteratif bir yöntem tanımlamıştır. Bu yöntemle yakınsama hızı artırılmış ve iyi bir genlik yanıtı elde edilecek şekilde eş dalgacıklı süzgeç (equiripple filter) tasarımı anlatılmıştır [3]. Jain ve Crochiere, iki kanallı QMF bankasının tasarımı için iteratif bir algoritma önermişlerdir. $\mathrm{Bu}$ algoritma her iterasyonda amaç fonksiyonunun özdeğer ve özvektörlerini bularak hesaplama yapmaktadır [4].

Cruesere ve Mitra, yüksek kalitede örnek süzgeç tasarlamak için temel bir metot sunmuşlardır. Bu metotta örnek süzgeç tasarımı için equiripple yaklaşımı kullanılarak hesaplama için geçen süre ve hesaplama karmaşası literatürdeki diğer çalışmalara göre azaltılmaktadır [5]. Çoklu hızlı süzgeç bankalarında ilk olarak frekans düzlemindeki işaret iki veya daha fazla işarete ayrılmakta ve alıcı uçta bu işaretler yeniden birleştirilerek gönderilen işaretin hızlı ve doğru bir şekilde elde edilmesi sağlanır. Süzgeç bankasında girişe uygulanan işaret farklı hızlardaki alt bantlara ayrılır. Farklı frekanslardaki veya diğer bir ifadeyle farklı hızlardaki bu işaretlere işaret işleme teknikleri uygulandıktan sonra çıkış işareti elde edilir [7]. 1975'ten sonra çoklu hızlı işaret işlemenin uygulama alanları artış göstermiştir. 1993'te Vaidyanathan, işaret işleme ile ilgili literatürde önemli bir yere sahip çalışmasında çoklu hızlı işaret işlemenin temellerini vererek süzgeç bankası uygulamasını anlatmış ve zamanla periyodik olarak değişen süzgeçler ile dalgacık dönüşümü arasındaki ilişkiyi tanımlamıştır [8].

$\mathrm{Bu}$ çalışmada, iteratif yöntem olarak bilinen ve en küçük hata ile istenen optimum dürtü yanıtını sağlayan en iyi yöntemlerden biri olan ParksMcClellan algoritması temel alınmıştır. Kesim frekansının optimize edilmesini temel alan ParksMcClellan algoritmasından farklı olarak ilk örnek süzgecin geçirme bandı frekansının optimize edilmesine dayalı bir algoritma geliștirilmiştir. Geliştirilen algoritma ile tasarlanan süzgeçler FIR (finite impuse responce-sonlu dürtü tepkili) olarak seçilmiştir. Süzgeç tasarımında pencereleme tekniği temel alınmış ve iki farklı pencerenin kaskat olarak bağlanmasına dayalı yeni bir pencere yapısı önerilmiştir. Tasarlanan iki kanallı QMF bankası, rastgele giriş işareti ve Mitral kapak Doppler işareti için test edilmiştir.

Çalışmanın ilk bölümünde pencereleme yöntemiyle FIR süzgeç tasarımı; ikinci bölümünde ise QMF bankası anlatılacaktır. Süzgeç tasarımında kullanılan optimizasyon algoritmaları ile ilgili bilgi üçüncü bölümde verildikten sonra farklı giriş işaretleri için süzgeç bankasının performansı dördüncü bölümde ayrıntılı olarak anlatıldıktan sonra; son bölümde sonuçlar verilecektir.

\section{PENCERELEME YÖNTEMIYLE FIR SÜZGEÇ TASARIMI (FIR FILTER DESIGN WITH WINDOWING TECHNIQUE)}

Pencereleme yönteminde ilk olarak nedensel olmayan sonsuz dürtü yanıtlı ideal bir frekans seçici süzgeç belirlenir ve doğrusal fazlı, nedensel, sonlu dürtü yanıtlı bir süzgeç bulunabilmesi için başlangıçta seçilen süzgecin birim dürtü yanıtı pencerelenir. Uygun bir pencereleme işlevi ve ideal bir süzgeç seçilmesi önemlidir. İdeal süzgeç, geçirme bandında birim genlik kazancı ve doğrusal faz karakteristiği, söndürme bandında ise sıfır genlik kazancı olan bir süzgeçtir. İdeal süzgecin pencerelenmesiyle elde edilecek sonlu dürtü yanıtlı süzgeç, doğrusal fazlı olacaktır [9-11]. Pencereleme yöntemiyle FIR süzgeç tasarımı, pencerenin yapısına göre sabit ve ayarlanabilir pencereleme yöntemleri olarak sinıflandırılmaktadır [12].

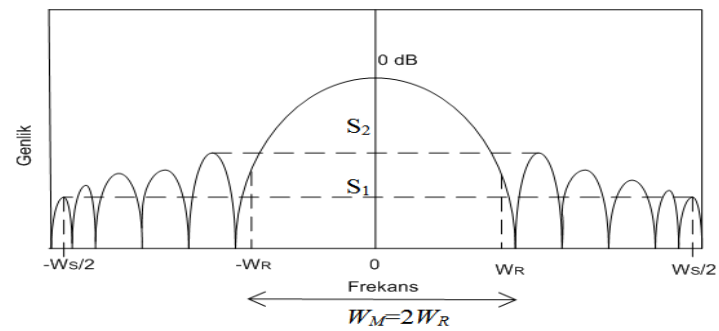

Şekil 1. Tipik bir pencerenin normalize genlik spektrumu (Normalized amplitude spectrum of a typical window)

Tipik bir pencerenin normalize genlik spektrumu Şekil 1 ile gösterilmiştir. Pencere performansının ayırt edici spektral karakteristik parametreleri; analob genişliği $W_{M}$, dalgalanma oranı (Ripple Ratio- tepecik oran1) $R$ ve yan lob azalma oranı $S$ 'dir. $W_{M}$ analob genişliği iki yarım analob genişliğini, $R$ Maksimum yanlob genliği ile analob genliğinin farkını, $S$ 'de maksimum yan lob genliği ile minimum yan lob genliğinin farkını temsil etmektedir. $N$ uzunluğa sahip bir pencere, zamana bağlı bir fonksiyon olarak $w(n T)$, $|n| \leq(N-1) / 2$ için sıfirdan farklı geri kalan aralıkta ise sifirdir $[13,21]$.

\section{SÜZGEÇ BANKASI TASARIMI (FILTER BANK DESIGN)}

Şekil 2'deki blok yapı iki kanallı sayısal çeyrek ayna süzgeç bankasını göstermektedir. Şekil 2'den görüldüğü gibi iki kanallı süzgeç bankasında $X(z)$ giriş işareti, eşit bant genişliğinde iki alt banda ayrılır. Bantlardan biri yüksek frekansları diğeri alçak frekansları geçirme özelliğine sahiptir. $H_{0}(z)$ alçak geçiren analiz süzgeci, $H_{1}(z)$ yüksek geçiren analiz süzgeci temsil etmektedir. $M$ analiz bankasında alt örnekleme oranını, sentez bankasında üst örnekleme oranını temsil etmektedir. Sentez bankasında $G_{0}(z)$ alçak geçiren sentez süzgecini $G_{1}(z)$ ise yüksek 
geçiren sentez süzgecini temsil etmektedir. QMF bankası çoklu hızlı sayısal süzgeç bankalarının bir alt grubudur [14-24].

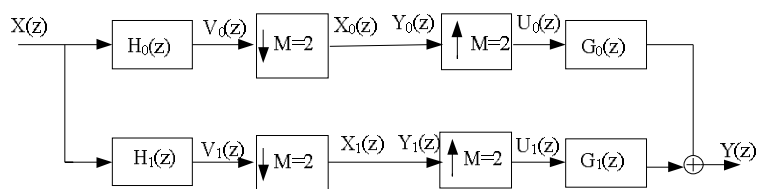

Şekil 2. İki kanallı QMF bankası (Two Channel QMF Bank)

İşaret işlemede sürekli zamanlı bir işareti ayrık zamanlı olarak elde etmek için örnekleme işlemi yapılır. Örnekleme frekansı analog işaretin maksimum frekansının iki katından daha yüksek olduğu durumda tekrarlanan frekans bantları arasında boşluklar oluşmaktadır. Örnekleme frekansı analog işaretin maksimum frekansının tam iki katına eşit olduğunda örneklenmiş işaretin frekans spektrumunda tekrar eden frekans bileşenleri uç uca gelmektedir. $\mathrm{Bu}$ durumda çakışma görülmez. Örnekleme frekansı analog işaretin maksimum frekansının iki katından küçük olduğu durumda ise analog işaret örnekleme frekanslarında tekrarlandığında örneklenmiş işaretin frekans spektrumunda çakışma meydana gelir. Yetersiz örnekleme nedeniyle örneklenmiş işaretin spektrumunda frekans bileşenlerinin çakışması, frekansta örtüşme olarak tanımlanmaktadır. Örtüşmenin olmadığ gecikmeye sahip olduğu sistemler en iyi yeniden yapılandırılmış (PR-Perfect Reconstruction) sistemler olarak adlandırılmaktadır. Giriş ve çıkış işaretleri arasında bir miktar gecikme ve genlikte bozulmanın olduğu sistemler ise yaklaşık en iyi yeniden yapılandırılmış (NPR-Near Perfect Reconstruction) sistemler olarak tanımlanmaktadır. $\mathrm{Bu}$ çalışmada, uygulamada gerçekleştirilebilir olan NPR süzgeç bankası tasarımı gerçekleştirilmiş ve farklı giriş işaretleri için süzgeç bankasının performansı değerlendirilmiştir.

\section{OPTIMMIZASYON (OPTIMIZATION ALGORITHM)}

Genellikle geçirme ve durdurma bantlarında farklı bozulmalara sahip süzgeçlerin tasarlanması istenir. Eğer bozulma fazla ise daha kısa FIR süzgeçler kullanarak bu sorun çözülebilir. Parks McClellan optimizasyon algoritması, geçirme ve durdurma bantlarında farklı bozulmalardaki eş dalgacıklı FIR süzgeçleri tasarlayan iteratif bir algoritmadır. $\mathrm{Bu}$ optimizasyon algoritması ile doğrusal fazlı FIR süzgeç tasarımı için Chebyshev hata yaklaşımı yöntemi kullanılarak minimizasyon yapılmaktadır. Chebyshev hata minimizasyonu yaklaşımı kullanıcıya özgü kısıtlamalar yaptığı için kullanışlı bir yöntemdir. Chebyshev hata fonksiyonunu minimize edecek doğrusal fazlı FIR süzgeçler Remez algoritmasını ya da doğrusal programlama tekniğini kullanırlar. Bu iki metot da iteratif sayısal ve genel amaçlı algoritmalardır. Remez algoritması etkili, optimal çözümlere hızlı yaklaşan, sıklıkla kullanılan bir tekniktir [15].

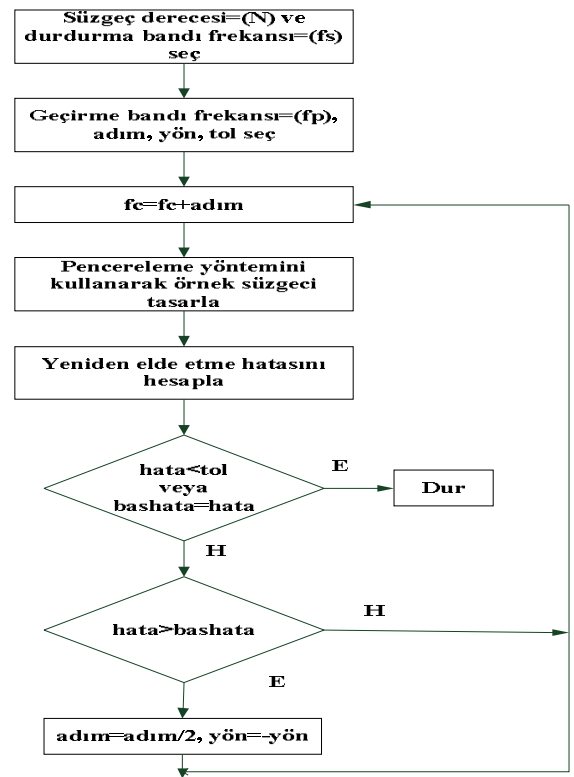

Şekil 3. Algoritmaya ait akış diyagramı (Flowchart of the algorithm)

Şekil 3'te, kullanılan optimizasyon algoritmasının akış şeması verilmektedir. Şekilden görüleceği gibi her iterasyonda $f_{c}$ kesim frekansı, amaç fonksiyonunu minimize etmek için adım büyüklüğü ile belirtilen aralıklarla artırılmaktadır. Böylece yeni süzgeç katsayıları hesaplanmakta ve $Q$ yeniden elde etme hatası, başlangıç hatası ile karşılaştırılmaktadır. Elde edilen sonuç başlangıç hatasından büyükse adım büyüklüğü yarıya düşürülmekte ve böylece arama yönü değiştirilmektedir. Ardışık adımlarla süzgeç istenilen özellikleri sağlayacak şekilde geliştirilmekte ve sonlandırma şartları sağlanınca da işlem sona erdirilmektedir.

QMF bankasına ait yeniden elde etme hatası, Denklem 1'de verilmektedir.

$Q=\max \left\{|H(w)|^{2}+\left|H\left(w-\frac{\pi}{2}\right)\right|^{2}-1\right\} \quad 0<w<\pi / 2$

Denklem 1'de $Q$, amaç fonksiyonunu yani optimize edilecek fonksiyonu tanımlamaktadır.

pre $=\max \mid 20 \log _{10}\left[\left|H_{0}^{2}(w)-H_{0}^{2}(w+\pi)\right|\right]$

pre (peak reconstruction error-tepe yeniden elde etme hatası) karşılaştırma kriteri olarak kullanılacaktır [2].

\section{FARKLI GİISŞ IŞARETLERİ IÇIIN QMF BANKASININ PERFORMANSI (QMF BANK'S PERFORMANCE FOR DIFFERENT INPUT SIGNALS)}

QMF bankası tasarımı için ilk olarak süzgeç bankaları Kaiser ve daha sonra Cosh pencereleriyle 
tasarlanacaktır. Uygulamalar Intel Pentium Core 2 Duo T5870 $2 \mathrm{GHz}$ işlemciye sahip 2 GB RAM ve Windows 7 özelliklerine sahip bir bilgisayarda Matlab kullanılarak gerçekleştirilmiştir. Kaiser ve Cosh pencerelerine ait denklemler sirasiyla 3,4 ve 5 'te verilmektedir. Denklem 3'teki $\beta$ Kaiser penceresine ait kontrol parametresini, $a_{c}$ ise Cosh penceresinin kontrol parametresini temsil etmektedir.

$$
\begin{array}{ll}
w_{1}(n)=\frac{I_{0}\left(\beta \sqrt{1-(2 n /(N-1))^{2}}\right)}{I_{0}(\beta)} & 0 \leq n \leq N \\
I_{0}(x)=1+\sum_{r=1}^{\infty}\left[\frac{(x / 2)^{r}}{r !}\right]^{2} & \\
w_{2}(n)=\left[\frac{\cosh \left(a_{c} \sqrt{1-(2 n /(N-1))^{2}}\right)}{\cosh \left(a_{c}\right)}\right] & 0 \leq n \leq N
\end{array}
$$

$\mathrm{Bu}$ çalışmada Kaiser ve Cosh pencerelerinin kaskat bağlanmasıyla elde edilen ve Kaiser-Cosh olarak adlandirilan bu pencere ile tasarlanan QMF bankalarının performansı, rastgele ve Mitral Kapak Doppler işareti için değerlendirilmiştir. Kaiser-Cosh penceresinin matematiksel eşitliği Denklem 6 ile verilmektedir.

$w(n)=0.5 *\left[\frac{I_{0}\left(a_{k h} \sqrt{1-(2 n /(N-1))^{2}}\right)}{I_{0}\left(a_{k h}\right)}+\frac{\cosh \left(a_{c h} \sqrt{1-(2 n /(N-1))^{2}}\right)}{\cosh \left(a_{c h}\right)}\right]$

Denklem 6'da verilen $a_{k h}$ ve $a_{c h}$ Kaiser-Cosh penceresi için sırasıyla Kaiser ve Cosh pencerelerinin yeni kontrol parametrelerini temsil etmektedir. Önerilen pencereyle tasarlanan süzgeç bankasının girişine ilk olarak rastgele bir işaret daha sonra da Mitral Kapak Doppler işareti uygulanmıştır. Uygulanan giriş işaretleri için pre, amaç fonksiyonunun en iyi değerini temsil eden $\mathrm{Q}$, zaman, iterasyon sayısı, durdurma bandı zayıflaması $A_{S}$, geçirme bandı zayıflaması $A_{p}$, MSE (Mean Square Error-ortalama karesel hata), SNR (Signal to Noise Ratio-sinyalin gürültüye oranı) ve PSNR (Peak Signal to Noise Ratio-sinyalin tepe değerinin gürültüye oran1) göz önüne alınarak değerlendirmeler yapılmıştır.

\subsection{Tasarlanan Süzgeç Bankasının Rastgele Giriş İşaretine Verdiği Çıkış (Response for Random Signal by Designed Filter Bank)}

Süzgeç bankasının girişine Matlab m-file kullanılarak üretilen rastgele bir işaret uygulanmış ve bu durumda süzgeç bankasının verdiği çıkış işareti izlenerek tasarlanan süzgeç bankasının performansı belirlenmiştir. Alt bölümlerde Kaiser, Cosh ve önerilen Kaiser-Cosh penceresi ile gerçekleştirilen uygulamalar sırasıyla anlatılmaktadır.

\subsubsection{Kaiser Penceresiyle Tasarım Uygulamaları (Design Applications with Kaiser Window)}

Kaiser penceresi ile gerçekleştirilen süzgeç bankasının analiz ve sentez süzgeçlerine ait genlik yanıtları dB olarak Şekil 4'te, analiz süzgeç bankası için pre ve genlik bozulmasındaki değişim Şekil 5'te verilmiştir. Şekil 6'da Kaiser penceresiyle tasarlanan QMF bankasına rastgele giriş işareti uygulandığında elde edilen frekans yanıtı gösterilmiştir.

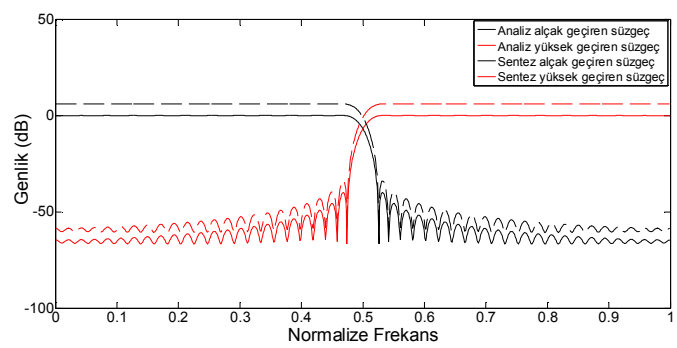

Şekil 4. Kaiser penceresiyle tasarlanan analiz ve sentez süzgeçlerin genlik yanıtları (Response of amplitude analysis and synthesis filter with Kaiser Window)

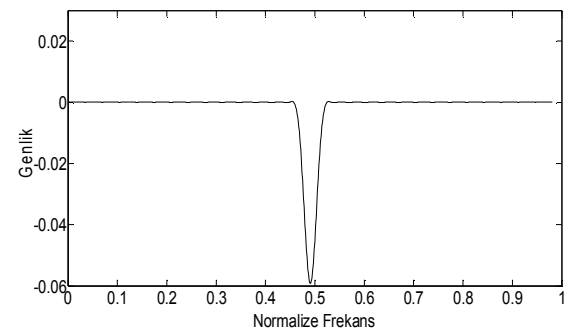

a)

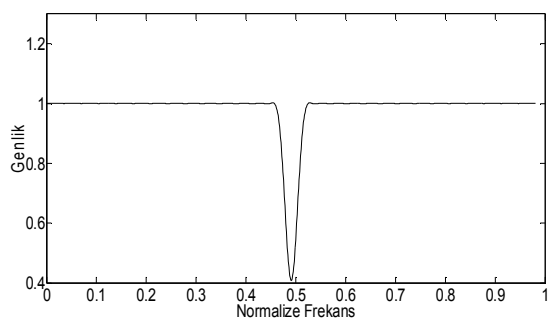

b)

Şekil 5. Kaiser ile analiz süzgeç için a) pre b) genlik bozulmasının değişimi (pre, response of amplitude analysis filter with Kaiser Window)

Tablo 1'de QMF Bankasının performansı çalışmada kullanılan tüm pencereler için karşılaştırmalı olarak verilmiştir. Kaiser penceresiyle $N=91$ için pre ve $Q$ için en iyi değerler, sirasıyla 0,0017 ve 0,0020 olarak 48 iterasyonda 0,3686 saniyede elde edilmiştir. $A_{s}$ ve $A_{p}$ değerleri de bu durumda en iyi olarak bulunmuştur. Tablo 2'de rastgele ve mitral kapak Doppler işareti için süzgeç bankasıyla elde edilen MSE ve SNR değerleri de tüm pencereler için karşılaştırmalı olarak verilmiştir. Tablo 2 incelendiğinde Kaiser penceresiyle MSE ve SNR için en iyi sonuçlar sirasıly $6,78 \mathrm{e}-5$ ve $\% 89,8146$ olarak $N=111$ için elde edilmiştir. 
Tablo 1. Farklı pencerelerle tasarlanan QMF Bankasının performans parametreleri (Performance parameters of QMF filter for different filter lengths)

\begin{tabular}{|c|c|c|c|c|c|c|}
\hline Pencere & $\boldsymbol{N}$ & pre & $\boldsymbol{Q}$ & $\begin{array}{c}\text { Süre } \\
(\mathbf{s})\end{array}$ & $\begin{array}{c}\boldsymbol{A}_{\boldsymbol{p}} \\
(\mathbf{d B})\end{array}$ & $\begin{array}{c}\boldsymbol{A}_{\boldsymbol{s}} \\
(\mathbf{d B})\end{array}$ \\
\hline \multirow{4}{*}{ Kaiser } & 51 & 0,0018 & 0,0021 & 0,3998 & 0,0045 & 73,5861 \\
\cline { 2 - 7 } & 71 & 0,0020 & 0,0023 & 0,3462 & 0,0051 & 72,6093 \\
\cline { 2 - 7 } & 91 & 0,0017 & 0,0020 & 0,3686 & 0,0043 & 740407 \\
\cline { 2 - 7 } & 111 & 0,0019 & 0,0022 & 0,2892 & 0,0048 & 73,0540 \\
\hline \multirow{4}{*}{ Cosh } & 51 & 0,0167 & 0,0194 & 0,3752 & 0,0419 & 80,3235 \\
\cline { 2 - 7 } & 71 & 0,0178 & 0,0207 & 0,3856 & 0,0447 & 79,7697 \\
\cline { 2 - 7 } & 91 & 0,0169 & 0,0196 & 0,3995 & 0,0423 & 80,2399 \\
\cline { 2 - 7 } Kaiser- & 111 & 0,0181 & 0,0211 & 0,4026 & 0,0456 & 79,5997 \\
\cline { 2 - 7 } Cosh & 51 & 0,0034 & 0,0039 & 0,3493 & 0,0085 & 94,1527 \\
\cline { 2 - 7 } & 91 & 0,0039 & 0,0045 & 0,5220 & 0,0099 & 92,8917 \\
\cline { 2 - 7 } & 111 & 0,0028 & 0,0033 & 0,3602 & 0,0071 & 95,7039 \\
\hline \multirow{3}{*}{}
\end{tabular}

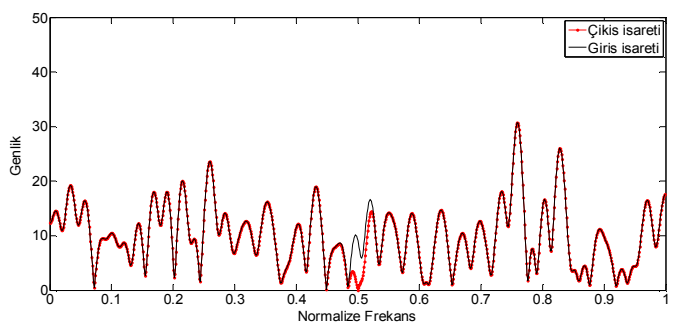

Şekil 6. Rastgele giriş için Kaiser ile tasarlanan QMF bankasının frekans yanıtı (Frequency Response of QMF Bank with Kaiser window for random input)

\subsubsection{Cosh Penceresiyle Tasarım Uygulamaları (Design Applications with Cosh Window)}

Cosh penceresi ile yapılan tasarımda elde edilen analiz ve sentez süzgeçlerinin genlik yanıtları dB cinsinden Şekil 7'de verilmiştir. Aynı süzgeç derecesinde analiz süzgeç için pre ve genlik bozulmasındaki değişim Şekil 8 'de, süzgeç bankasının rasgele giriş işareti için verdiği frekans yanıtı ise Şekil 9'da verilmiştir. Bu durumda elde edilen sonuçlar Tablo 1 ve 2'de gösterilmektedir. $N=51$ için pre, $Q$ ve $A_{s}$ için en iyi değerler sirasıyla $0,0167,0,0194$ ve $80,3235 \mathrm{~dB}$ olarak 47 iterasyonda 0,3752 s de elde edilmiştir. MSE ve SNR için en iyi sonuçlar ise $N=91$ için sirasiyla $1,43 \mathrm{e}-4$ ve $\% 86,5616$ olarak bulunmuştur.

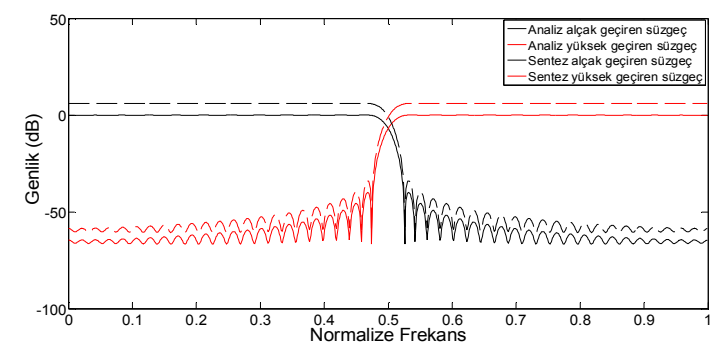

Şekil 7. Cosh penceresiyle tasarlanan analiz ve sentez süzgeçlerin genlik yanıtları (Response of amplitude analysis and synthesis filter with Cosh Window)

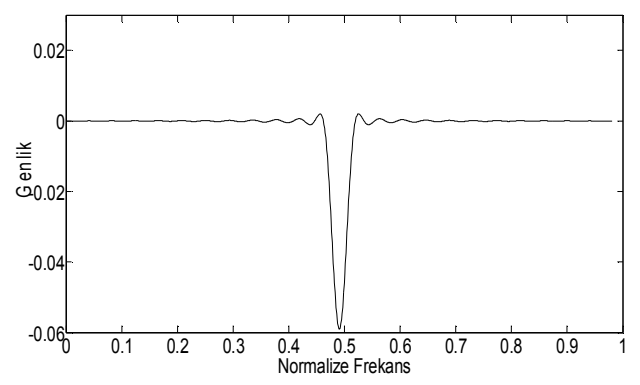

a)

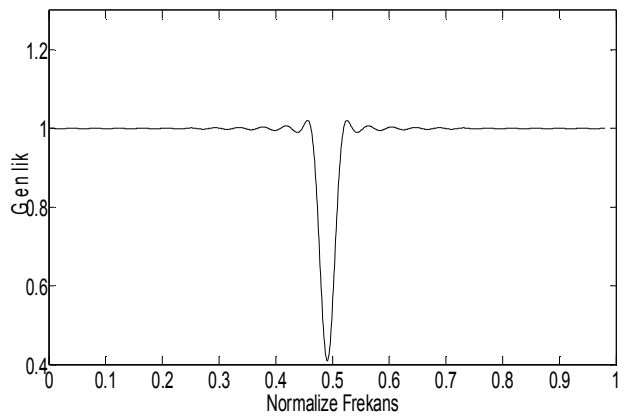

b)

Şekil 8. Cosh ile analiz süzgeç için a) pre b) genlik bozulmasının değişimi (pre, response of amplitude analysis filter with Cosh Window)

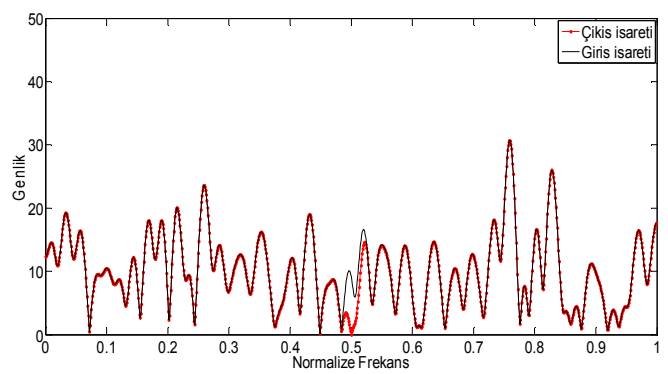

Şekil 9. Rastgele giriş için Cosh ile tasarlanan QMF bankasının frekans yanıtı (Frequency Response of QMF Bank with Cosh Window for random input) 


\subsubsection{Kaiser-Cosh Penceresi ile Tasarım Uygulamaları (Design Applications with Kaiser-Cosh Window)}

Önerilen Kaiser-Cosh penceresi kullanılarak gerçekleştirilen süzgeç bankası tasarımında elde edilen analiz ve sentez süzgeçlere ait genlik yanıtları dB cinsinden Şekil 10'da verilmiştir. Analiz süzgeç için pre ve genlik bozulmasındaki değişim Şekil 11 'de verilmektedir.

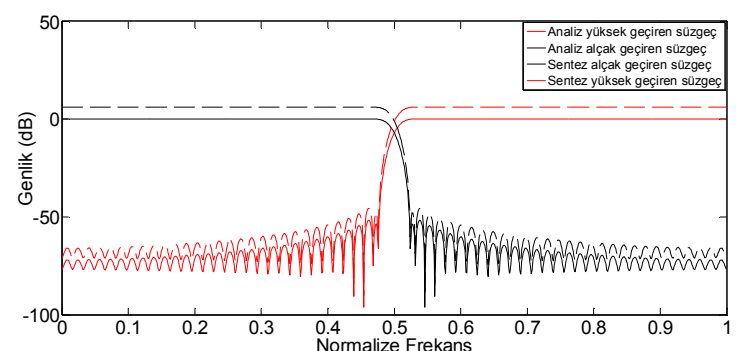

Şekil 10. Kaiser-Cosh penceresiyle analiz ve sentez süzgeçlere ait alçak ve yüksek geçiren süzgeçlerin genlik yanıtları (Response of amplitude analysis and synthesis filter with Kaiser-Cosh Window)

Şekil 12'de Kaiser-Cosh penceresiyle tasarlanan süzgeç bankasının analiz ve sentez bankasını oluşturan alçak ve yüksek geçiren süzgeçlerin frekans yanıtları, Şekil 13'te Kaiser-Cosh penceresiyle tasarlanan süzgeç bankasına rastgele giriș işareti uygulandığı durumda elde edilen frekans yanıtları verilmiştir. $\mathrm{Bu}$ durumda çıkışın girişi izlediği fakat geçiş bandında giriş işareti ile çıkış işareti arasında bir miktar bozulma olduğu görülmektedir.

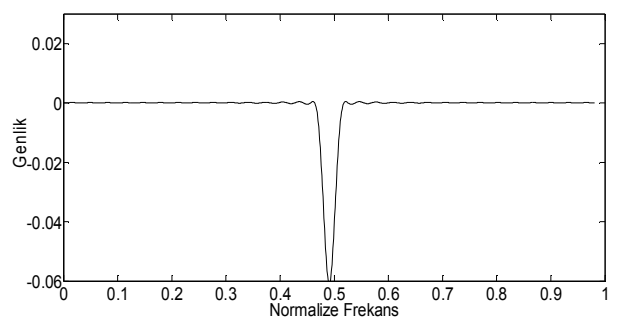

a)

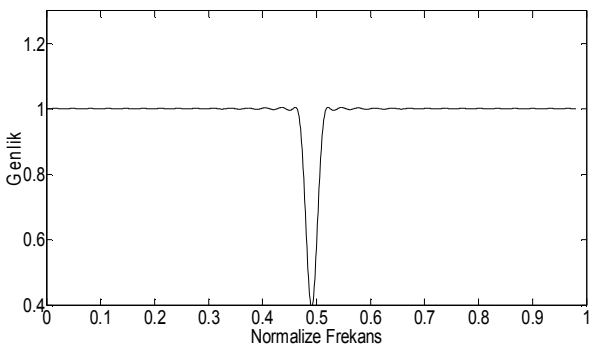

b)

Şekil 11. Kaiser-Cosh penceresi ile tasarlanan analiz süzgeç için a) pre b) genlik bozulmasındaki değişim (pre, response of amplitude analysis filter with Kaiser-Cosh Window)

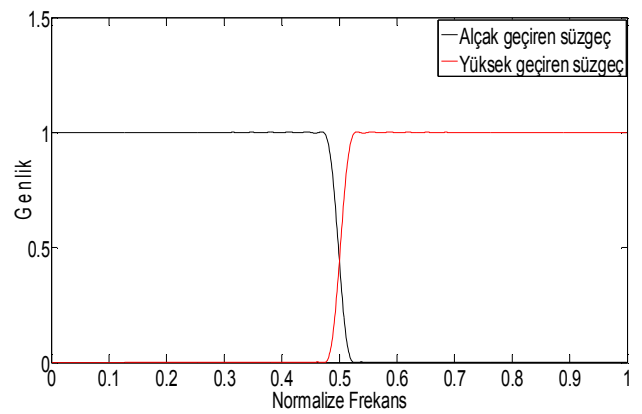

a)

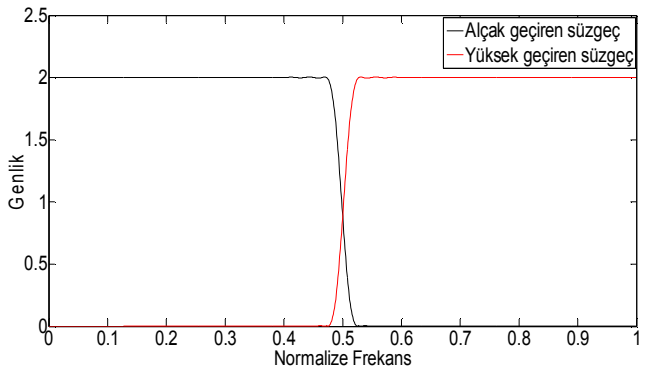

b)

Şekil 12. Kaiser-Cosh penceresi ile elde edilen a) analiz b) sentez süzgecin frekans yanıtı (Frequency Response of analysis and synthesis filter)

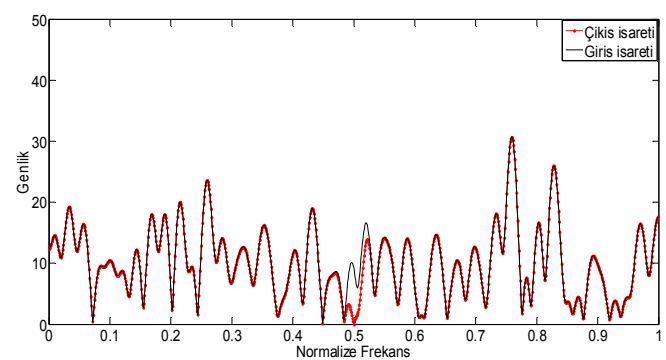

Şekil 13. Rastgele giriş için Kaiser-Cosh ile tasarlanan QMF bankasının frekans yanıtı (Frequency Response of QMF Bank with Kaiser-Cosh Window for random input)

Şekil 14'te Kaiser, Cosh ve Kaiser-Cosh pencereleriyle yapilan uygulamalar sonrasinda elde edilen işaretlerin değişimi gösterilmektedir. KaiserCosh penceresi kullanıldığ durumda pre, $Q$ ve $A_{s}$ için en iyi değerler sırasıyla $0,0028,0,0033$ ve $95,7039 \mathrm{~dB}$ olarak $N=91$ için 47 iterasyonda $0,3602 \mathrm{~s}$ de elde edilmiştir. MSE ve SNR için en iyi sonuçlar ise $N=111$ için sırasıly $3,69 \mathrm{e}-5$ ve $\% 92,4535$ olarak bulunmuştur.

Kaiser, Cosh ve Kaiser-Cosh pencereleri için elde edilen sonuçlar değerlendirildiğinde Kaiser-Cosh penceresinin daha iyi durdurma bandı zayıflaması sağladığı görülmektedir. Fakat önerilen pencere kullanıldığında tepe yeniden elde etme hatası Kaiser penceresiyle yapılan tasarıma göre artmaktadır. 


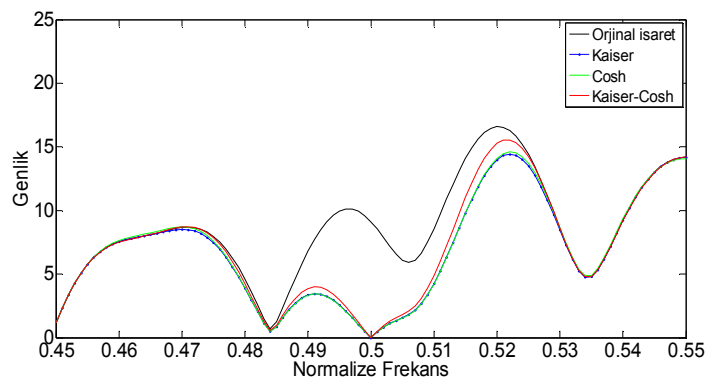

Şekil 14. Tasarlanan süzgeç bankalarındaki geçiş band1 dalgalanması (Passband ripple in the designed filter banks)

5.2. Tasarlanan Süzgeç Bankasının Mitral Kapak Doppler İşaretine Verdiği Çıkış (Response for Mitral Valve Doppler Signal by Designed Filter Bank)

QMF bankasına giriş işareti olarak Erciyes Üniversitesi Eğitim ve Araştırma Hastanesi Kardiyoloji servisinden alınan Mitral Kapak Doppler işareti uygulanmıştır.

Doppler ekokardiyografi işaretler GE Vivid 7 cihazı ile elde edilmiştir. Sistem donanımı; sayısal Doppler ultrason ünitesi, Doğrusal ultrason probu, giriş-çıkış kartı ve kişisel bilgisayardan oluşmaktadır. Kayıt sırasında sabit prop uygulama açısı ve cihaz ayarları kullanılmıştır. Ultrason cihazı ses çıkışı için kullanılan örnekleme frekansı $44100 \mathrm{~Hz}$ dir. Süzgeç bankasının girişine Şekil 15'teki işaret uygulanmıştır [10]. Şekil 15 'te verilen işaretin 250 örneklik kısmı kullanılarak uygulamalar gerçekleştirilmiştir.

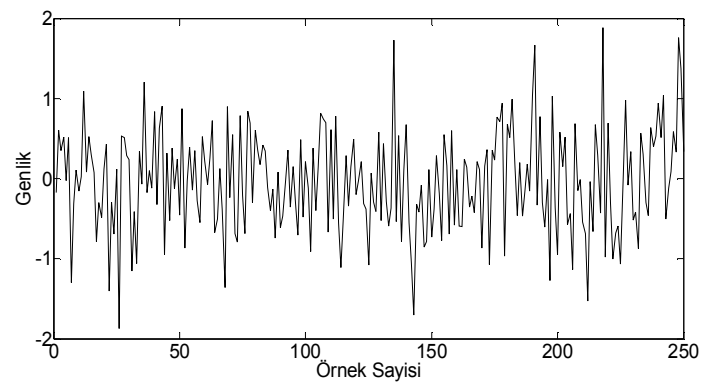

Şekil 15. Süzgeç bankasının girişine uygulanan Mitral Kapak Doppler işaretinin 250 örneklik kısmı (Examples of Mitral Valve Doppler Signal)

5.2.1.Mitral Kapak Doppler İşareti için Kaiser Penceresi ile Tasarım Uygulamaları (Design Applications for Mitral Valve Doppler Signal with Kaiser Window)

Kaiser penceresiyle tasarlanan süzgeç bankasının analiz ve sentez süzgeçlerine ait genlik yanıtları dB olarak Şekil 16'da, analiz süzgeç için pre ve genlik bozulmasındaki değişim Şekil 17'de verilmiştir.

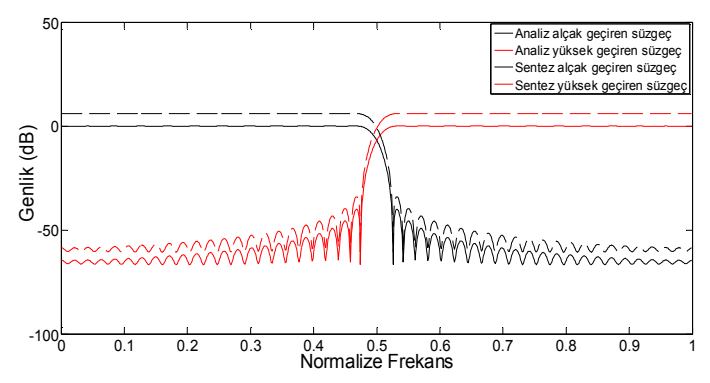

Şekil 16. Kaiser penceresiyle tasarlanan süzgeç bankasının analiz ve sentez süzgeçlerine ait genlik yanıtları (Amplitude response of analysis and synthesis filter with Kaiser window)

Tasarlanan süzgeç bankasına mitral kapak Doppler işareti giriş olarak uygulandığında elde edilen çıkış işareti Şekil 18'de verilmiştir. Şekil 18'den çıkış işaretinin geçiş bölgesinde bir miktar bozulmayla birlikte giriş işaretini izlediği gözlenmektedir.

Kaiser penceresiyle tasarlanan süzgeç bankası tasarımında farklı süzgeç dereceleri için elde edilen sonuçlar karşılaştırmalı olarak Tablo 2'de verilmiştir. Tablo 2'den görüleceği gibi MSE ve SNR için en iyi sonuçlar ise $N=111$ için sırasıyla 0,0249 ve $\%$ 64,1690 olarak bulunmuştur.

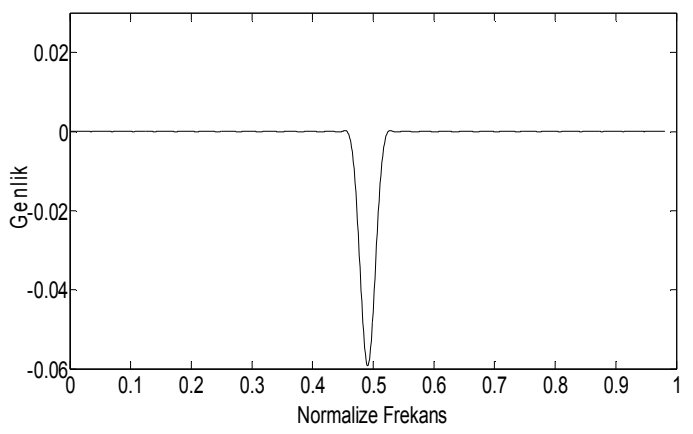

a)

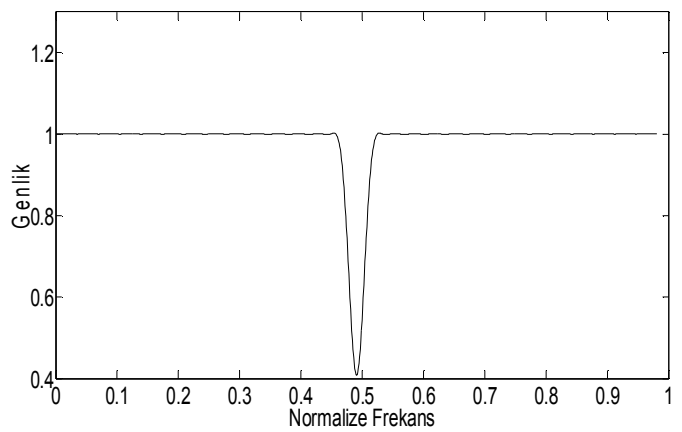

b)

Şekil 17. Kaiser penceresi ile tasarlanan analiz süzgeç için a) pre b) genlik bozulmasının değişimi (pre, response of amplitude analysis filter with Kaiser window) 


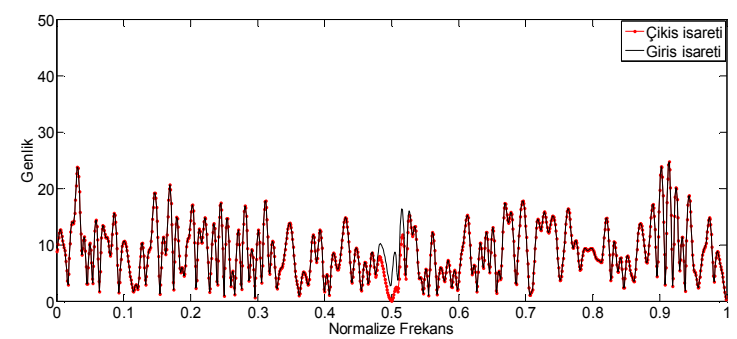

Şekil 18. Kaiser penceresi ile tasarlanan QMF bankasının frekans yanıtı (Frequency response of QMF bank with Kaiser window)

\subsubsection{Mitral Kapak İşareti için Cosh Penceresi ile Tasarım Uygulamaları (Design Application for Mitral Valve Doppler Signal with Cosh Window)}

Şekil 19'da Cosh penceresiyle tasarlanan süzgeç bankasının analiz ve sentez süzgeçlerine ait genlik yanıtları $\mathrm{dB}$ cinsinden verilmiştir. Cosh penceresiyle tasarlanan süzgeç bankasında analiz süzgeç için pre ve genlik bozulmasındaki değişim Şekil 20'de gösterilmiştir.

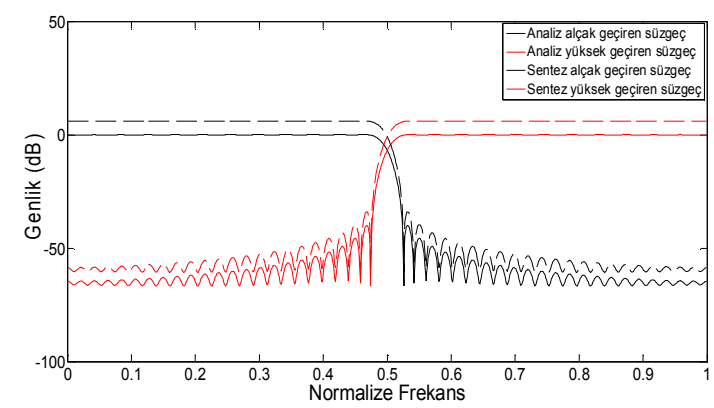

Şekil 19. Cosh penceresiyle tasarlanan süzgeç bankasının analiz ve sentez süzgeçlerine ait genlik yanitları (Amplitude response of analysis and synthesis filter with Cosh window)

Cosh penceresiyle tasarlanan süzgeç bankasının mitral kapak Doppler işaretine verdiği yanıt Şekil 21'de gösterilmiştir. Kaiser penceresi kullanıldığı durumdakine benzer olarak, Şekil 21'de de çıkış işaretinin geçiş bölgesinde bir miktar bozulmayla birlikte giriş işaretini izlediği gözlenmektedir.

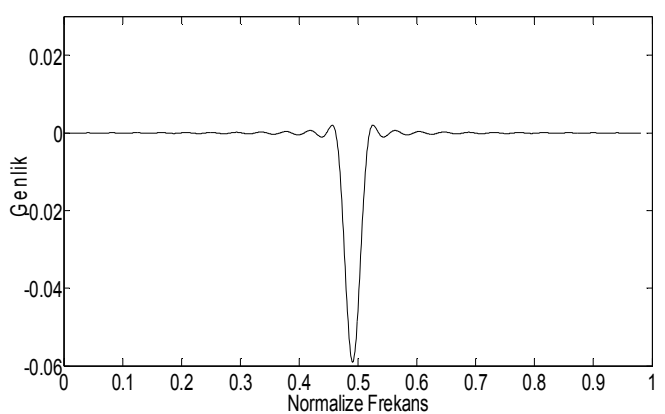

a)

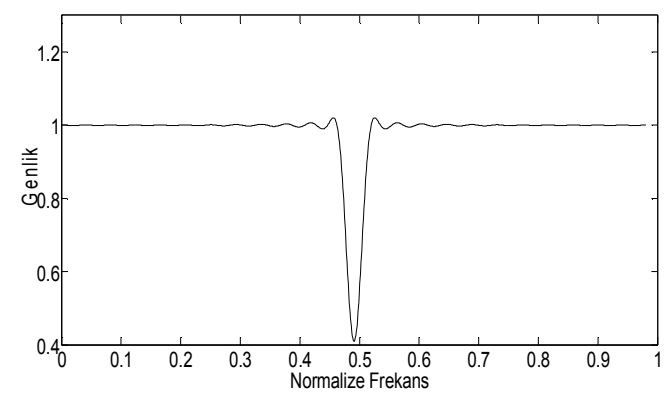

b)

Şekil 20. Cosh penceresi ile tasarlanan analiz süzgeç için a) pre b) genlik bozulmasının değişimi (pre, response of amplitude analysis filter with Cosh window)

Cosh penceresiyle tasarlanan süzgeç bankasının girişine Mitral Kapak Doppler giriş işareti uygulanması halinde elde edilen sonuçlar Tablo 2'de verilmiştir. Cosh penceresi ile MSE ve SNR için en iyi sonuçlar süzgecin derecesinin 111 olması durumunda sirasiyla 0,0218 ve $\% \quad 64,7470$ olarak bulunmuştur.

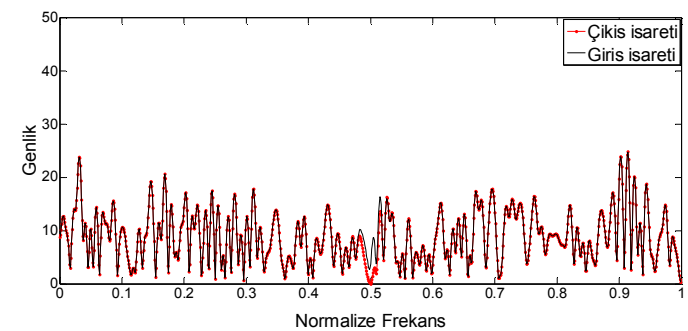

Şekil 21. Cosh penceresi ile tasarlanan QMF bankasının frekans yanıtı (Frequency response of QMF bank with Cosh window)

Tablo 2. Farklı giriş işaretleri için elde edilen MSE ve SNR değerleri (MSE and SNR values for different input signals)

\begin{tabular}{|c|c|c|c|c|c|}
\hline $\begin{array}{c}\text { Kullanılan } \\
\text { Pencere }\end{array}$ & $\begin{array}{c}\text { Süzgeç } \\
\text { Derecesi }\end{array}$ & \multicolumn{2}{|c|}{ Rastgele işaret } & \multicolumn{2}{|c|}{$\begin{array}{c}\text { Mitral Kapak } \\
\text { Doppler İşareti }\end{array}$} \\
\cline { 2 - 6 } & $\boldsymbol{N}$ & MSE & $\begin{array}{c}\text { SNR } \\
\mathbf{( \% )}\end{array}$ & MSE & $\begin{array}{c}\text { SNR } \\
\mathbf{( \% )}\end{array}$ \\
\hline \multirow{4}{*}{ Kaiser } & 51 & 0,0062 & 70,1787 & 0,0333 & 62,9072 \\
\cline { 2 - 6 } & 71 & 0,0017 & 75,7391 & 0,0310 & 63,2229 \\
\cline { 2 - 6 } & 91 & $6,91 \mathrm{e}-4$ & 79,7319 & 0,0280 & 63,6546 \\
\cline { 2 - 6 } & 111 & $6,78 \mathrm{e}-5$ & 89,8146 & 0,0249 & 64,1690 \\
\hline \multirow{4}{*}{ Cosh } & 51 & 0,0033 & 72,9296 & 0,0335 & 62,8750 \\
\cline { 2 - 6 } & 71 & $5,86 \mathrm{e}-4$ & 80,4479 & 0,0288 & 63,5354 \\
\cline { 2 - 6 } & 91 & $1,43 \mathrm{e}-4$ & 86,5616 & 0,0246 & 64,2154 \\
\cline { 2 - 6 } & 111 & $2,48 \mathrm{e}-4$ & 84,1730 & 0,0218 & 64,7470 \\
\hline \multirow{4}{*}{$\begin{array}{c}\text { Kaiser- } \\
\text { Cosh }\end{array}$} & 71 & 0,0047 & 71,4469 & 0,0342 & 62,7889 \\
\cline { 2 - 6 } & 91 & 0,0012 & 77,3276 & 0,0293 & 63,4651 \\
\cline { 2 - 6 } & 111 & $3,64 \mathrm{e}-4$ & 82,5174 & 0,0262 & 63,9434 \\
\cline { 2 - 6 } & & 92,4535 & 0,0237 & 64,3849 \\
\hline
\end{tabular}


5.2.3. Mitral Kapak İşareti için Kaiser-Cosh Penceresi ile Tasarım Uygulamaları (Design Applications for Mitral Valve Doppler Signal with Kaiser-Cosh Window)

Kaiser-Cosh penceresiyle tasarlanan süzgeç bankasının genlik yanıtları Şekil 22'de, analiz süzgeç için pre ve genlik bozulmasındaki değişim Şekil 23 'te, analiz ve sentez süzgeçlerin frekans yanıtları ise Şekil 24'te verilmiştir.

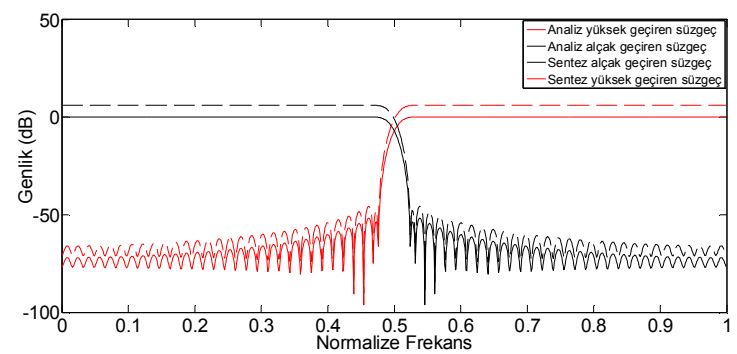

Şekil 22. Kaiser-Cosh penceresiyle tasarlanan süzgeç bankasının analiz ve sentez süzgeçlerine ait genlik yanıtları (Amplitude response of analysis and synthesis filter with Kaiser-Cosh Window)

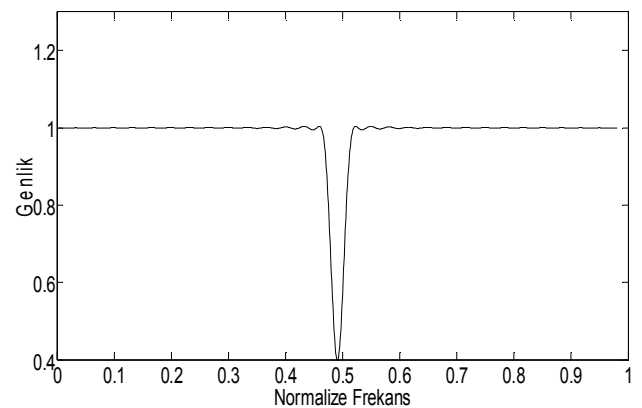

a)

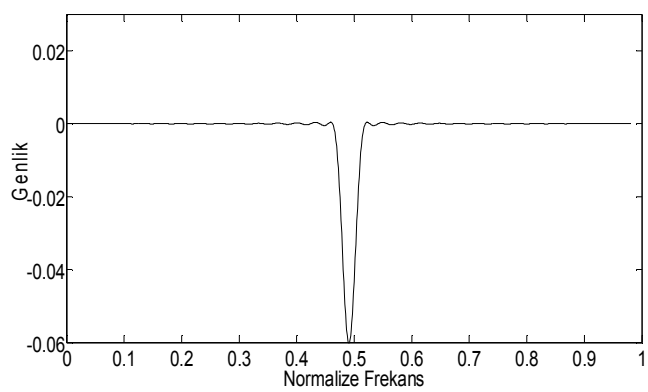

b)

Şekil 23. Kaiser-Cosh penceresi ile tasarlanan analiz süzgeç için a) pre hatası b) genlik bozulmasının değişimi (pre, response of amplitude analysis filter with KaiserCosh window)

Kaiser-Cosh penceresiyle tasarlanan süzgeç bankasının mitral kapak Doppler işaretine verdiği yanıt Şekil 25'te verilmiştir. Kaiser ve Cosh pencereleri ile gerçekleştirilen tasarımlara benzer şekilde Şekil 26'dan de çıkış işaretinin geçiş bölgesinde bir miktar bozulmayla birlikte giriş işaretini izlediği gözlenmektedir. Önerilen pencereyle tasarlanan süzgeç bankası için elde edilen sonuçlar Tablo 2'de gösterilmektedir.

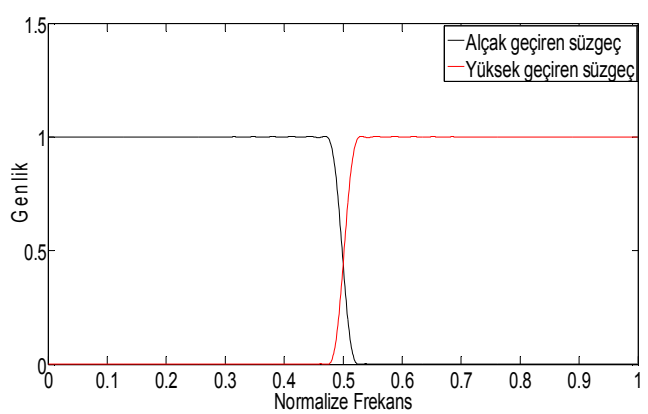

a)

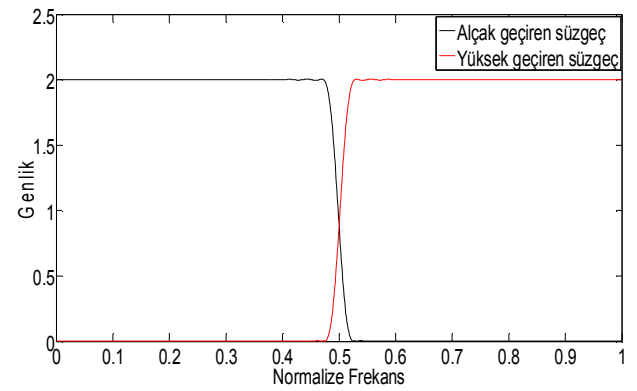

b)

Şekil 24. a) Analiz ve b) sentez süzgeçlerin frekans yanitı (Frequency response of analyis and synthesis filters)

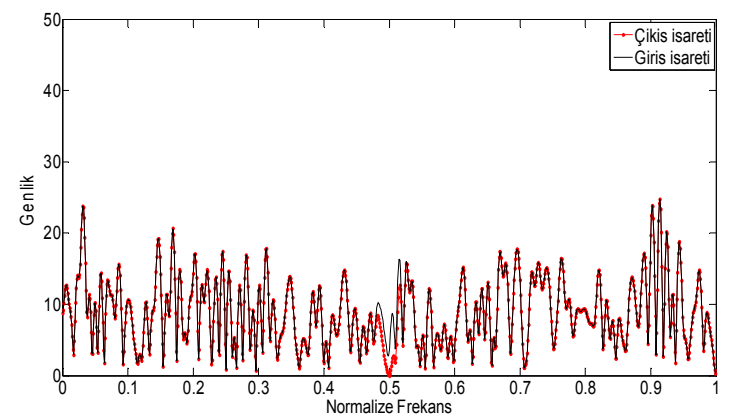

Şekil 25. Kaiser-Cosh penceresiyle tasarlanan süzgeç bankasının giriş ve çıkış işaretlerinin frekans yanıtı (Frequency Response of filter bank)

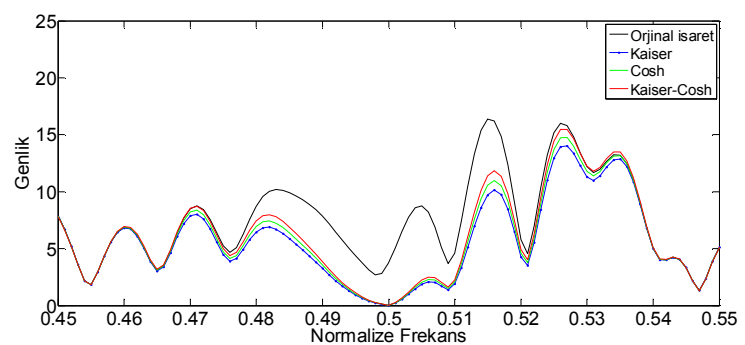

Şekil 26. Tasarlanan süzgeç bankalarındaki geçiş band1 dalgalanması (Passband ripple in the designed filter bank)

Kaiser-Cosh penceresi kullanıldığı durumda MSE ve SNR için en iyi sonuçlar $N=111$ için sirasıyla 0,0237 ve \% 92,4535 olarak bulunmuştur. Tüm pencereler birlikte değerlendirildiğinde Kaiser-Cosh penceresinin daha iyi durdurma bandı zayıflaması sağladığı 
görülmektedir. Önerilen pencere kullanıldığında durumda tepe yeniden elde etme hatası, rastgele işaret kullanılması durumuna benzer şekilde, Kaiser penceresi ile gerçekleştirilen tasarıma göre biraz artmaktadır.

\section{3. Önerilen Süzgeç Bankası için Performans} Karşılaştırılması (Performance Comparison of Purposed Filter Bank)

Tablo 3'te QMF bankası tasarımı için önerilen pencere ve literatürde kullanılan diğer çalışmalar karşılaştırılarak verilmektedir. Literatürdeki çalışmalara uygun olması açısından; Kaiser penceresi için ilk örnek süzgeç tasarımında durdurma bandı zayıflaması $A_{s}=60 \mathrm{~dB}$ ve $\beta=5.65326$ olarak kullanıldığından, önerilen süzgeç için de bu değerler aynı kullanılmıştır. Yine uygunluk açısından süzgeç bankasının dereceleri 32 ve 64 olarak alınmıştır. $a_{w}=0,2$ için süzgeç derecesinin 64 olması durumunda, Ramakrishna A. ve arkadaşlarının çalışmalarında pre için 0,0410 ve $A_{s}$ için $60 \mathrm{~dB}$, Kamislioglu B. ve arkadaşlarının çalışmalarında da, pre için 0,0082 ve $A_{s}$ için 74,4853 dB değeri elde edilmiştir. Önerilen pencere ile gerçekleştirilen tasarımlarda ise 71,8185 $\mathrm{dB}$ ile en iyi durdurma bandı zayıflamasına ulaşılmıştır. Süzgeç bankasının derecesi değişse bile önerilen pencere ile yaklaşık 46-48 iterasyonda optimal tasarımlar gerçekleştirilmiştir. $a_{w}{ }^{\prime}$ nin 0,1 olması durumunda da önerilen pencere ile $a_{w}{ }^{\prime}$ nin 0,2 durumundakine yakın değerler elde edilmiştir.
Tablo 3 incelendiğinde $a_{w}=0,1$ için süzgeç derecesinin 32 olması durumunda, Chen C. K. ve arkadaşlarının çalışmalarında pre için 0,0012 ve $A_{s}$ için $36,9700 \mathrm{~dB}$, $\mathrm{Xu} \mathrm{H}$. ve arkadaşlarının çalışmalarında da, pre için 0,0018 ve $A_{s}$ için $60,9600 \mathrm{~dB}$ değerleri elde edilmiştir. Önerilen hibrit pencereyle gerçekleştirilen tasarımlarda ise $72,1546 \mathrm{~dB}$ ile en iyi durdurma bandı zayıflamasına ulaşılmıştır. $a_{w}$ 'nin 0,2 olması durumunda, önerilen pencereyle gerçekleştirilen tasarımlar için daha küçük pre $(0,0040)$ ve daha iyi durdurma bandı zayıflaması elde edildiği görülmektedir.

\section{SONUÇLAR (RESULTS)}

$\mathrm{Bu}$ çalışmada sayısal işaret işlemede önemli bir yere sahip olan QMF bankası tasarımında Kaiser ve Cosh pencerelerinin hibrit olarak kullanımına dayalı yeni bir pencere tekniği önerilmiş ve bu teknikle tasarlanan süzgeç bankalarının performansı farklı giriş işaretleri için test edilmiştir. Gerçekleştirilen uygulamalar sonucunda önerilen Kaiser-Cosh penceresi, Kaiser ve Cosh pencerelerinin tek olarak kullanılması durumuna göre durdurma bandı zayıflaması, pre, Q, iterasyon sayıs1 ve zaman gibi parametreler bakımından iyi sonuçlar vermiştir. Kaiser-Cosh penceresi ile hem pre hem de $A_{s}$ bakımından literatürdeki diğer pencerelerle yapılan çalışmalara göre daha iyi sonuçlar elde edildiğinden QMF tasarımında önerilen pencerenin kullanımı tercih edilebilir.

Tablo 3. Literatürdeki farklı pencereler ve önerilen pencere ile tasarlanan QMF bankasının performansı (Performance comparison using the proposed algorithm with respect to other algorithm)

\begin{tabular}{|c|c|c|c|c|c|c|c|}
\hline$N$ & $\begin{array}{c}\text { Kullanılan Pencereleme } \\
\text { Yöntemi }\end{array}$ & $a_{w}$ & pre & $\begin{array}{l}\text { zaman } \\
(\mathrm{s})\end{array}$ & $\begin{array}{c}A_{p} \\
(\mathrm{~dB})\end{array}$ & $\begin{array}{c}A_{s} \\
(\mathrm{~dB})\end{array}$ & $\begin{array}{l}\text { İter. } \\
\text { say. }\end{array}$ \\
\hline \multirow{9}{*}{32} & Chen C. K. ve ark.[3] & 0,1 & 0,0012 & 2,4200 & 0,0537 & 36,9700 & - \\
\hline & Xu H. ve ark. [17] & 0,1 & 0,0018 & 0,3900 & 0,0532 & 60,9600 & - \\
\hline & $\begin{array}{c}\text { Kaiser-Cosh } \\
\text { (Önerilen yaklașım ) }\end{array}$ & 0,1 & 0,0014 & 0,1072 & 0,0034 & 72,1546 & 46 \\
\hline & Kaiser & 0,2 & 0,0225 & 0,4530 & 0,0056 & 63,8261 & 45 \\
\hline & Cosh & 0,2 & 0,0160 & 0,3223 & 0,0821 & 46,2374 & 48 \\
\hline & $\begin{array}{l}\text { Ramakrishna A. ve ark. } \\
\text { (Chebyshev yön.) [14] }\end{array}$ & 0,2 & 0,0460 & 0,6870 & 0,0060 & 60,0000 & 160 \\
\hline & Creusere C. D. ve ark. [5] & 0,2 & 0,0560 & 4,8430 & 0,0070 & 60,0000 & 414 \\
\hline & $\begin{array}{l}\text { Ramakrishna A. ve ark. } \\
\text { (Kaiser yön.) [14] }\end{array}$ & 0,2 & 0,0660 & 0,7810 & 0,0115 & 60,0000 & 150 \\
\hline & $\begin{array}{c}\text { Kaiser-Cosh } \\
\text { (Önerilen yaklașım ) }\end{array}$ & 0,2 & 0,0040 & 0,1364 & 0,0100 & 72,7228 & 47 \\
\hline \multirow{6}{*}{64} & $\begin{array}{c}\text { Kaiser-Cosh } \\
\text { (Önerilen yaklaşım ) }\end{array}$ & 0,1 & 0,0048 & 0,1039 & 0,0120 & 71,1927 & 46 \\
\hline & Kaiser & 0,2 & 0,0199 & 0,4572 & 0,0050 & 64,8203 & 44 \\
\hline & Cosh & 0,2 & 0,0139 & 0,4427 & 0,0822 & 46,2127 & 48 \\
\hline & $\begin{array}{l}\text { Ramakrishna A. ve ark. } \\
\text { (Chebyshev yön.)[14] }\end{array}$ & 0,2 & 0,0410 & 0,7000 & 0,0025 & 60,0000 & 154 \\
\hline & Kamislioglu B. ve ark. [15] & 0,2 & 0,0082 & 0,4364 & 0,0026 & 74,4853 & 46 \\
\hline & $\begin{array}{c}\text { Kaiser-Cosh } \\
\text { (Önerilen yaklașım ) }\end{array}$ & 0,2 & 0,0045 & 0,3104 & 0,0111 & 71,8185 & 46 \\
\hline
\end{tabular}




\section{TEŞEKKÜR (ACKNOWLEDGEMENT)}

$\mathrm{Bu}$ çalışma Erciyes Üniversitesi Bilimsel Araştırma Birimi tarafindan FYL-2013-4569 kodu ile desteklenmektedir. Yazarlar bu çalışmaya verdikleri destekten dolayı Erciyes Üniversitesi Bilimsel Araştırma Birimine ve Mitral Kapak Doppler işaretinin alınması için verdiği katkılardan dolayı Türker Koza’ya teşekkür ederler.

\section{KAYNAKLAR (REFERENCES)}

1. Jain A., Saxena R. ve Saxena S. C., "A Simple Alias Free QMF System with Near Perfect Reconstruction", Indian Institute of Science, Cilt 85, No 1, 1-10, 2005.

2. Johnston J. D., "A Filter Family Design For Use in Quadrature Mirror Filter Banks", IEEE International Conference on Acoustics Speech and Signal Processing, Cilt 5, 291-294, 1980.

3. Chen C. K. ve Lee J. H., "Design of Quadrature Mirror Filters with Linear Phase in Frequency Domain”, IEEE Trans Circuits System, Cilt 39, No 9, 593-605, 1992.

4. Jain V. K. ve Crochiere R. E., "Quadrature Mirror Filter in Time Domain", IEEE Transactions on Acoustics Speech Signal Processing, Cilt 32, 353-361,1984.

5. Creusere C. D. ve Mitra S. K., "A Simple Method for Designing High-Quality Prototype Filters for $M$-Band Pseudo QMF Banks", IEEE Transactions on Signal Processing, Cilt 43, No 4, 1005-10, 1995.

6. Kumar, A., Singh, G. K. ve Anand, R. S., "An Improved Method for Designing Quadrature Mirror Filter Banks Via Unconstrained Optimization”, Springer Science, Cilt 9, No 1, 99-111, 2010.

7. Karaağaç, M.E., Çoklu Hızlı İşaret İşleme Yöntemleriyle İşaretlerin Elde Edilmesi, Yüksek Lisans Tezi, İTÜ, Fen Bilimleri Enstitüsü, İstanbul, 2007.

8. Vaidyanathan, P. P., Multirate Systems and Filter Banks, Brendan M. Stevard, Prentice Hall, 07632, United States of America, 1993.

9. Ertürk, S., Sayısal İşaret İşleme, Birsen Yayınevi İstanbul, 2009.

10. Kamislioglu B., Koza T., Kockanat S. ve Karaboga N., "Noise Cancellation on Mitral Valve Doppler Signal with IIR Digital Filter Using Harmony Search Algorithm", Innovations in Intelligent Systems and Applications (INISTA), 1-5, 2013.

11. Kamişlioglu B. ve Karaboga N., "QMF Bank Design with Kaiser-Hamming Window Functions", International Symposium on Innovations in Intelligent SysTems and Applications (INISTA), 2014.
12. Kamislioglu B. ve Karaboga N., "Pencereleme Teknikleriyle FIR QMF Bankası Tasarımı", URSI International Union of Radio Science Türkiye Ulusal Komitesi, ELAZIĞ " $28-30$ Ağustos 2014".

13. Kamislioglu B., Yeni Çeyrek Ayna Süzgeç Bankası Tasarımı ve Uygulamaları, Yüksek Lisans Tezi, Erciyes Üniversitesi Fen Bilimleri Enstitüsü, KAYSERİ, 2014.

14. Ramakrishna, A. ve Nigam, M. J., "A Simple Method to Design FIR Qmf Banks", IEEE Elektronik Computer Engineering Intelligent Sensing and Information Processing (ICISIP), 236-239, 2006.

15. Kamislioglu B. ve Karaboga N., "Pencereleme Yöntemleriyle FIR QMF Bankası Tasarımı", IEEE 22. Sinyal İşleme ve İletişim Uygulamaları Kurultayı, SIU-2014, 23-25 Nisan.

16. Rafi, S. M., Kumar, A. ve Singh, G. K., "An Improved Particle Swarm Optimization Method for Multirate Filter Bank Design", Journal of the Franklin Institute, Cilt 350, No 4, 757-769, 2013.

17. $\mathrm{Xu}, \mathrm{H} ., \mathrm{Lu}, \mathrm{W}$. S. ve Antoniou, A., "An Improved Method for the Design of FIR Quadrature Mirror-İmage Filter Banks", IEEE Signal Processing Letters, Cilt 46, No 5, 12751281, 1998.

18. Jain, A., Rajiv, S. ve Saxena, S. C., "A Simple Alias-Free Qmf System with Near-Perfect Reconstruction", Journal of the Indian Institute of Science, Cilt 85, 1-10, 2005.

19. Anurag S. ve Kumar A., "Non-Uniform Filter Bank Design Using Modified Window Functions", Computational Intelligence and Signal Processing, 165-170, 2012.

20. Kumar A., Rafi S.M. ve Singh G. K., "A Hybrid Method for Designing Linear-Phase Quadrature Mirror Filter Bank", Digital Signal Processing, Cilt 22, 453-462, 2012.

21. Kumar A., Verma M. ve Lamba V.K., "Analysis of Modified Cosh Window Function and Performance Evaluation of the FIR Filter Designed Using Windowing Techniques", International Journal of Computers and Technology, Cilt 3, No 2, 324-328, 2012.

22. Kok C., Siu W. ve Law Y., "Peak Constrained Least-Squares QMF Banks", Signal Processing, Cilt 88, 2363-2371, 2008.

23. Sahu, O. P., Soni, M. K. ve Talwar, I. M., "Marquardt Optimization Method to Design Two-Channel Quadrature Mirror Filter Banks", Digital Signal Processing, Cilt 16 870-879, 2006.

24. $\mathrm{Xu}, \mathrm{H}$., Lu, W. ve Antoniou A., "Improved Iterative Methods for the Design of Quadrature Mirror-Image Filter Banks", IEEE Signal Processing Letters, Cilt 43 No 5, 363-371, 1996. 
